This is an Open Access article, distributed under the terms of the Creative Commons

Attribution licence (http://creativecommons.org/licenses/by/4.0/), which permits unrestricted re-use, distribution, and reproduction in any medium, provided the original work is properly cited.

doi:10.1017/So1 $44686 X_{1} 6001203$

\title{
Let's talk about sex - what do older men and women say about their sexual relations and sexual activities? A qualitative analysis of ELSA Wave 6 data
}

\author{
JOSIE TETLEY*, DAVID M. LEE $\uparrow$, JAMES NAZROO† and \\ SHARRON HINCHLIFF
}

\begin{abstract}
In $2012 / 2013$ the English Longitudinal Study of Ageing (ELSA) included a comprehensive Sexual Relationships and Activities Questionnaire (SRA-Q). A total of 7,079 men and women mainly aged $5^{\circ}$ to $>90$, primarily heterosexual and in a coupled relationship, completed the SRA-Q answering a series of questions about their attitudes to sexual relationships, their own sexual activities, problems and concerns with sexual functioning, and quality of intimate relationships. The questions aimed to gain insights into the ways in which sexual relations and activities related to health, wellbeing and other lifestyle factors change as people grow older. The primary mode of data collection was a tick box response to a series of questions. However, at the end of the questionnaire an open comment box was provided, which asked respondents whether there was anything else that they would like to say; 1,084 respondents provided additional information and these comments created a unique qualitative data-set. The analysis of the data then illustrated how people's health, relationships, experiences and perceptions of ageing, along with sexual satisfaction, impact on sexual relationships and activities.
\end{abstract}

KEY WORDS - sexual relations, sexual activities, well-being, health, ageing, population-based, ELSA.

* Faculty of Health, Psychology and Social Care, Manchester Metropolitan University, UK.

$\dagger$ Cathie Marsh Institute for Social Research, School of Social Sciences, The University of Manchester, UK.

\$ School of Nursing \& Midwifery, The University of Sheffield, UK. 


\section{Introduction}

Older people are living longer, but research on sexual activity and relationships in later life has maintained its focus on issues of decline, dysfunction and dissatisfaction (Domoney 2009; Hayes and Dennerstein 2005; Karraker, DeLamater and Schwartz 2011; Syme et al. 2013). While there is an increasing body of evidence around sexual relations and sexual activities in later life (Byers 2010; Carpenter, Nathanson and Kim 2006; Karraker and DeLamater 2013), few studies have explored sexual lifestyles among older people based on large, representative population-based samples. Moreover, in terms of understanding why decline, dysfunction and dissatisfaction have been the focus of previous research, the representative studies that exist have had a predominately biomedical focus (Field et al. 2013; Laumann et al. 2005; Lindau et al. 2007) and centred almost exclusively on individuals and individualistic models of relationships, while largely ignoring the significance of relational dynamics, discordance, diversity and satisfaction. In addition, the quantitative methods (mainly selfadministered questionnaires) employed in large-scale studies on sexuality place constraints upon the range of sexual behaviours that can realistically be assessed. While this reflects practical limitations inherent to structured questionnaire methods of data capture, it raises the question of how well we can understand sexuality in later life by quantifying it in terms of frequency of activities and problems. It has then been recommended that more research is required that focuses on understanding what older people themselves identify as the social, cultural and relationship contexts in which sexual relationships take place (DeLamater 2012; Galinsky and Waite 2014; Vares et al. 2007). Moreover, it is important to acknowledge that much of the research on sexuality and sexual behaviours in later life is drawn from heterosexual participants and based on heteronormative ideas about sexual experiences. Less is known, therefore, about the diversity of sexual experiences in later life (Vares et al. 2007). There is then the need to consider more critically heteronormative constructions of sexuality in the context of older men and women's lives and relationships.

Against this backdrop this paper contributes to the evidence base in this field in three ways. First, by presenting the theoretical and empirical understandings that have historically underpinned research related to ageing and sexual activities and relationships to illustrate why more qualitative research is required. Second, by analysing qualitative data, gathered in an open-text box that was part of a large-scale representative survey, to illustrate how such data can provide additional understandings on older couples' experiences of their sexual relationships. Third, by highlighting the ways that health, 
gender and relationship issues can influence sexual relationships and activity in later life.

\section{Decline, dysfunction, dissatisfaction and sexual relationships in later life}

The majority of empirical research studies on the sexual activities and relationships of men and women in later life have tended to centre on the negative dimensions of sexual activity: physical decline, compromised function and dissatisfaction (Domoney 20o9; Karraker, DeLamater and Schwartz 2011; Tiefer 2007). Moreover, a primarily biomedical discourse in the literature has focused on a suggested normality of sexual function as penetrative sex, with an emphasis on erections, failing to acknowledge the heterogeneity of sexual experiences across the lifespan (DeLamater and Koepsel 2015; Katz and Marshall 2003). This is a particularly pertinent issue when considering that older couples may increasingly value emotional intimacy, such as kissing and cuddling, over penetrative sex (Galinsky and Waite 2014; Hinchliff and Gott 2004).

More recently, sexuality and sexual function across the lifecourse have been considered within an inclusive theoretical framework, where biological (health and disease), social (relationship quality and dynamics) and psychological (attitudes and knowledge) factors interact to influence sexual expression (Carpenter and DeLamater 2012). Such an approach provides a strong starting point from which to examine how positive sexuality and intimate partnerships relate to, and possibly influence, changing physical, mental and social resources with increasing age. While previous research has developed our understandings about the extent to which older people experience sexual problems, it is valuable to develop a broader understanding of older people's thoughts and experiences about sex and their relationships. From the perspective of a positive health paradigm (Rosen and Bachmann 2008), an important question is to what extent sexual activities and problems are independently associated with an individual's wellbeing, happiness and quality of life (Syme et al. 2013). Also, much of the previous research literature has almost entirely focused on individualistic models of sexual health and not considered the impacts of the coupled relationship.

\section{Sexual relations and older couples}

Research that explores sexual relations in the context of a coupled relationship is important as gerontology often fails to deal with the issue of how 
partners interact in a partnership (DeLamater 2012; Gledhill and Schweitzer 2014). The literature around sexual intimacy in later life suggests that this has been due, in part, to a focus on medically managing changes that impact on the ability of a couple to engage in penetrative sexual activities as the main form of sexual intimacy, as opposed to understanding the broader ways in which couples experience sexual intimacy (DeLamater and Sill 2005). Understanding the changing role of penetrative sex in a coupled relationship is particularly important, as DeLamater and Sill (2005) suggest that a couple may end their sexual lives together if one or both of them see penetrative sex as the only acceptable form of sexual activity and expression within their relationship.

The focus on maintaining penetrative sex can also lead to other aspects of physical and emotional satisfaction within a relationship being overlooked. For example, in their study on the importance of sex in later life, Gott and Hinchliff (2003) found that older people not only reported sexual intimacy as important, but also valued it as a way of maintaining their relationship and expressing love. However, they also found that when penetrative sex became less important or ceased, older people were more able to cope with this when they were in a long-standing relationship (Gott and Hinchliff 2003). Sexual activity and physical intimacy are, nevertheless, important to connections between partners, but the overall quality of a relationship has been found to impact on sexuality and wellbeing in a coupled relationship (Lee et al. 2016b; Waite and Das 2010).

\section{Sexual relationships, gender and later life}

For older people, there are important lifecourse differences in sexual partnering from a gender perspective (Araujo et al. 2004). More specifically, heterosexual women of every age are less likely than their male counterparts to report being sexually active, and when they are sexually active they have fewer partners (Carpenter, Nathanson and Kim 2006). Other conceptions of sexual activity and sexual relations highlight how men and women are viewed differently, particularly in later life. For example, middle-aged women without a partner have been labelled as a potential 'danger' to younger men: a sexually aggressive cougar, which has both positive and negative connotations for women (Montemurro and Siefken 2014). While being described as a cougar can be an offensive term, other studies have suggested that the metaphor can suggest that older women can be sexually strong and in control (Lawton, Callister and Street 2010; Montemurro and Siefken 2014). Recognising that there are these conceptions of women and sexual activities in later life is important as recent 
research has identified that older women do want control over their sexual activities, but understandings and personal experiences of sex, desire and relationships in later life are still governed by dominant norms of ageing, gender and sexuality (Fileborn et al. 2015). In contrast, for older men, research tends to focus on issues associated with erectile function and how this impacts on masculinity, sexuality and intimate relationships (Gott 2005; Jung and Schill 2004; Oliffe 2005; Schwarz 2005). For both men and women, one response to supporting sexual activity in later life has been through the increasing medicalisation of sexual activity, including the development of sexuo-pharmaceuticals like Viagra (for men's erections) and Flibanserin (for women's sexual desire), which does not account for the more complex relationship issues experienced by men or women (Gott 2005; Hollander 2006).

Acknowledging the complexities of these issues, the sexual experiences of older people can then be more fully understood by the use of qualitative data. The latest wave of the English Longitudinal Study of Ageing (ELSA) included a comprehensive Sexual Relationships and Activities Questionnaire (SRA-Q). A recently published paper based on the statistical evidence gathered by the SRA-Q identified the prevalence of sexual activity and reported levels of sexual health concerns (Lee et al. 2016a), however, the SRA-Q also included space for qualitative comments to be made. These qualitative data are important as they provide an opportunity to make sense more fully of subjective understandings of sexuality-related transitions and relationships in later life.

\section{Methods and data}

The ELSA is a nationally representative panel survey of community-dwelling men and women aged $5^{\circ}$ years and older in England. Full details on the study design and methods have been described previously (Steptoe et al. 2013). However, in Wave 6 (conducted in 2012/2013), a new instrument was included which aimed to capture data on sexual relationships and activities in later life. Out of a total of 10,601 individuals who participated in Wave 6, 7,079 $(67 \%)$ completed and returned the paper-based ELSA SRA-Q. The SRA-Q included questions on attitudes to sex, frequency of sexual activities and behaviours, problems with sexual activities and function, concerns and worries about sexual activities, function and relationships, and details about current sexual partnerships. Wave 6 participants completed the SRA-Q in private and sealed the questionnaire in an envelope upon completion. There were male and female versions of the SRA-Q, which are available from the ELSA website (http://www.elsa-project.ac.uk). At the end of the questionnaire there was a free text box and participants were 
invited to provide any additional comments. The specific prompt asked: 'If there is anything else you would like to tell us, please write in the space below. We shall be very interested to read what you have to say.' A total of 1,084 people completed this section. Table 1 lists the characteristics of participants who provided additional comments as part of the ELSA SRA-Q.

An additional analysis of the ELSA participant characteristics was also undertaken to identify if there were any statistically significant differences between the participants who wrote additional comments and those who did not (see Table 2). Those providing comments were slightly older, more likely to be female, have poorer self-rated health and drink alcohol less frequently compared to those who did not leave comments. It is the qualitative data from this self-selecting sub-sample of the ELSA participants that has been analysed and forms the basis of this paper.

ELSA Wave 6 received ethical approval from the NRES Committee South Central - Berkshire, and all participants were provided with a letter and leaflet to allow them to give informed consent. All the qualitative comments were anonymised and reviewed by the data holders to ensure that no disclosive statements were included in the final data-set released to the research team.

\section{Data analysis}

The ELSA qualitative data were different from typical semi/un-structured interview data, as the additional comments at the end of the SRA-Q were mainly short responses because of the limited space provided. Moreover, the quantity, fragmented and brief nature of these responses potentially limited the findings that could be drawn from the data. Despite these limitations, it is acknowledged that rigorous analysis of qualitative comments gathered as part of a survey can enrich the understandings of people's perceptions, attitudes and experiences (ten Kleij and Musters 2003). In response to these issues, Template Analysis, an established method of analysing qualitative data, was used as it offers a pragmatic approach for analysing a wide range of textual data (Cox 2008; Crabtree and Miller 1999; King 2012). This can include diary entries, text from electronic interviews or open-ended question responses on a written questionnaire (Brooks and King 2012). Template Analysis is not bound to any one epistemological position and can be adapted for use across a range of approaches (King 2004). Moreover, the flexibility of this approach means that it can be used to analyse qualitative data collected in the context of a mainly quantitative study (Brooks et al. 2015), including in this case where the responses to structured questions were used to examine which factors were associated with sexual activities and behaviours. 
T A B L E 1. Characteristics of women and men who provided comments in the free text box as part of the English Longitudinal Study of Ageing Sexual Relationships and Activities Questionnaire (SRA-Q)

\begin{tabular}{|c|c|c|}
\hline Variable & Women & Men \\
\hline $\mathrm{N}$ & 668 & 395 \\
\hline Age: & & \\
\hline$<5^{\circ}$ & $18(2.7)$ & $4(1.0)$ \\
\hline $5^{\mathrm{O}-59}$ & $146(21.8)$ & $61(15 \cdot 3)$ \\
\hline $6 o-69$ & $273(40.7)$ & $141(35 \cdot 3)$ \\
\hline $70-79$ & $172(25.6)$ & $133(33 \cdot 3$ \\
\hline $80+$ & $62(9.2)$ & $60(15.0$ \\
\hline \multicolumn{3}{|l|}{ Current partner: } \\
\hline Married/co-habiting & $4^{10}(61.2)$ & $295(73.9$ \\
\hline Divorced/separated & $79(11.8)$ & $39(9.8)$ \\
\hline Never married & $33(4.9)$ & $27(6.8)$ \\
\hline Widowed & $148(22.1)$ & $38(9.5)$ \\
\hline \multicolumn{3}{|l|}{ Age left education: } \\
\hline$\leqslant 14$ & $43(6.4)$ & $37(9 \cdot 3)$ \\
\hline $15^{-18}$ & $479(71.4)$ & $269(67.4)$ \\
\hline$\geqslant 19$ & $149(22.2)$ & $93(23.3$ \\
\hline \multicolumn{3}{|l|}{ Self-rated general health: } \\
\hline Excellent/very good & $286(42.6)$ & $145(36.5)$ \\
\hline Good & $199(29.7)$ & $127(32.0)$ \\
\hline Fair/poor & $186(27.7)$ & $125(31.5)$ \\
\hline \multicolumn{3}{|l|}{ Self-reported sexual experiences: ${ }^{1}$} \\
\hline Entirely/mostly with opposite sex & $634(94.9)$ & $380(96.2)$ \\
\hline \multicolumn{3}{|l|}{ Self-reported sexual desires: ${ }^{1}$} \\
\hline Entirely/mostly with opposite sex & $625(93.6)$ & $379(96.0)$ \\
\hline \multicolumn{3}{|l|}{ Smoking status: } \\
\hline Current & $70(10.4)$ & $45(11.3)$ \\
\hline \multicolumn{3}{|l|}{ Frequency of alcohol consumption: ${ }^{2}$} \\
\hline Never/rarely & $249\left(3^{8.3}\right)$ & $78(20.4)$ \\
\hline Regularly & $277(42.5)$ & $205(53 \cdot 7)$ \\
\hline Very frequently & $125(19.2)$ & $99(25 \cdot 9$ \\
\hline
\end{tabular}

Notes: Complete descriptive data are only available for 1,063 respondents. 1. Questions about lifetime sexual experiences and sexual desires were included at the end of the SRA-Q. 2. Frequency of alcohol consumption over the past year (never $/$ rarely $=$ never or once or twice a year; regularly $=$ once every two months to twice a week; very frequently $=$ three days a week to daily).

Procedurally, Template Analysis involves the development of a coding 'template', which summarises themes identified in a data-set, and organises them in a meaningful and useful manner. Initial themes are identified by looking at a small sub-section of the data. This 'template' is then used to analyse the whole data-set. During analysis, the template is modified as new themes emerge, while some themes may be dropped. This process continues until a final template is defined and the whole data-set has been coded (King 2004). In terms of the ELSA data-set and in line the with 
T A B LE 2. Characteristics of participants who did or did not provide comments in the free text box as part of the English Longitudinal Study of Ageing Sexual Relationships and Activities Questionnaire (SRA-Q)

\begin{tabular}{|c|c|c|c|}
\hline Variable & Comments & No comments & $p^{1}$ \\
\hline $\mathrm{N}$ & 1,063 & 6,016 & \\
\hline Mean age $(\mathrm{SD})$ & \multicolumn{2}{|c|}{ Frequencies (\%) } & $<0.001$ \\
\hline \multicolumn{4}{|l|}{ Gender: } \\
\hline Female & $668(62.8)$ & $3,287(54.6)$ & \multirow[t]{2}{*}{$<0.001$} \\
\hline Male & $395(37.2)$ & $2,729(45 \cdot 4)$ & \\
\hline \multicolumn{4}{|l|}{ Age (years): } \\
\hline$<50$ & $22(2.1)$ & $123(2.0)$ & \multirow[t]{5}{*}{$<0.001$} \\
\hline $5^{0-59}$ & $205(19 \cdot 3)$ & $1,634(27.2)$ & \\
\hline $60-69$ & $411(38.7)$ & $2,365(39.3)$ & \\
\hline $70-79$ & $303(28.5)$ & $1,410(23 \cdot 4)$ & \\
\hline $80+$ & $122(11.5)$ & $484(8.1)$ & \\
\hline \multicolumn{4}{|l|}{ Current partner: } \\
\hline Married/co-habiting & $702(66.1)$ & $4,224(70.2)$ & \multirow[t]{4}{*}{$<0.001$} \\
\hline Divorced/separated & $114(10.7)$ & $733(12.2)$ & \\
\hline Never married & $60(5 \cdot 7)$ & $349(5.8)$ & \\
\hline Widowed & $186(17.5)$ & $709(11.8)$ & \\
\hline \multicolumn{4}{|l|}{ Age left education: } \\
\hline$\leqslant 14$ & $80(7.5)$ & $414(6.9)$ & \multirow[t]{3}{*}{$0.3^{8}$} \\
\hline $15^{-18}$ & $742(69.8)$ & $4,324(71.9)$ & \\
\hline$\geqslant 19$ & $241(22.7)$ & $1,277(21.2)$ & \\
\hline \multicolumn{4}{|l|}{ Self-rated general health: } \\
\hline Excellent/very good & $429(40.4)$ & $2,620(43.6)$ & \multirow[t]{3}{*}{0.009} \\
\hline Good & $325(30.6)$ & $1,911(31.8)$ & \\
\hline Fair/poor & $309(29.1)$ & $1,483(24.7)$ & \\
\hline \multicolumn{4}{|l|}{ Self-reported sexual experiences: ${ }^{2}$} \\
\hline \multirow{2}{*}{\multicolumn{4}{|c|}{ Self-reported sexual desires: ${ }^{2}$}} \\
\hline & & & \\
\hline Entirely/mostly with opposite sex & $1,004(94.5)$ & $5,700(94.8)$ & 0.69 \\
\hline \multicolumn{4}{|l|}{ Smoking status: } \\
\hline Current & $115(10.8)$ & $744(12.4)$ & 0.16 \\
\hline \multicolumn{4}{|l|}{ Frequency of alcohol consumption: ${ }^{3}$} \\
\hline Never/rarely & $327(31.6)$ & $1,637(27.9)$ & 0.02 \\
\hline Regularly & $482(46.6)$ & $2,981(50.8)$ & \\
\hline Very frequently & $225(21.8)$ & $1,252(21.9)$ & \\
\hline
\end{tabular}

Notes: SD: standard deviation. 1. Value for difference between 'comments' and 'no comments groups'. 2. Questions about lifetime sexual experiences and sexual desires were included at the end of the SRA-Q. 3. Frequency of alcohol consumption over the past year (never/rarely = never or once or twice a year; regularly = once every two months to twice a week; very frequently = three days a week to daily).

'template' approach, we initially started with 20 data samples, including ten men and ten women. These were used to create an initial 'template' that identified how medications, long-term health conditions, relationships, ageing, sexual satisfaction and attitudes to sex impacted on older people's sexual relations and activities. Working from this initial template, the full 
data-set of 1,o84 qualitative comments was then analysed, using a process of grouping and sorting (King and Horrocks 2010; Waring and Wainwright 20o8) to produce a final template, which closely reflected the themes in the initial template. The strong link between the initial and final themes was not unexpected as the proceeding questions in the SRA-Q may well have influenced the issues that people reflected on when giving their end of survey comments, reducing the variation in content. This issue is further considered when discussing the limitations and conclusions of the study.

\section{Findings}

Four main themes emerged from the analysis. The first theme, health, illustrated how personal and partner health impacted on people's sexual relationships and activities. The analysis of the data also revealed how health and sexual relations were particularly affected by long-term conditions and gendered aspects of sexual health such as erectile problems and the menopause. The second theme, relationships, illustrated gender differences in the way that the importance of relationships was described, with women's comments being striking and outweighing male comments on the importance, or the lack thereof, of relationships. The third theme, sexual satisfaction, reflected how older people achieved, or experienced difficulties achieving, sexual satisfaction individually and in the context of a partnered relationship. The final theme, ageing and sexuality, reflected how both men and women experienced, and adapted, their sexual and intimate relationships in later life. These themes, which overlap with each other, are now presented with participants' quotations extracted from the data-set. As participant quotations are short, due to the way the data were collected, the quotes selected were those that most illustratively reflected the key issues within the themes.

\section{Health}

Health conditions most commonly mentioned as impacting on sexual activities included chronic obstructive pulmonary disease (COPD), cardiovascular disease and hypertension, prostate problems, diabetes and cancer, particularly breast cancer. Health conditions and/or the medicines prescribed had an impact on participants' sex lives in a number of ways. Participants wrote about erection problems and the loss of sexual desire, which they viewed as being caused by their medication. They also talked about physical incapacity as the result of, for example, arthritis, which 
limited their ability to engage in physical sexual activities. This was illustrated through comments such as:

How can I solve erectile problems, I suffer from blood pressure and diabet[es]. (Man aged $60-70$ )

The fact that I have rheumatoid arthritis and COPD after a [lobe] of my left lung was removed, I have physical limitations! (Man aged 70-80)

While physical health conditions clearly impacted on sexual activities, the comments of participants also illustrated how mental wellbeing and an interplay between physical and mental health impacted on sexual activities and desires for both men and women.

...because of the anti-depressant medication I am taking. For six months, while I have been taking this medication I have had no sex drive. (Man aged $5^{\mathrm{O}-60}$ )

Since going through the menopause and suffering from clinical depression this has all contributed to me not having any sexual desires. (Woman aged $5^{\mathrm{o}-60}$ )

There was, however, a distinct gender difference in the ways that men and women viewed the impact of their health on their sexual activities and relationships. Men made explicit reference to the individual impact of health conditions to sexual activities. In contrast, women were more likely to talk about health-related sexual difficulties in the context of their current relationship. Two examples, from male and female participants, illustrate this point:

Loss of sexual drive mostly attributable to medication for hypertension and prostate problems. (Man aged 70-80)

Breast cancer operations (three) and radiotherapy, left me with painful breast, rib area and shoulders, sexual relations with my husband dropped off dreadfully. Although we feel very close, it's a concern that we don't have sex very often. (Woman aged 6o-70)

Occasionally, comments were made about the health status of partners and how this impacted on sexual activities and relationships. For example:

During the last month my husband has been recovering from a hip replacement plus prior to operation the pain did have an effect on our sex life. (Woman aged 6o-70)

Men tended to comment on the impact of their partner's health on sexual activity less frequently than women did, a finding also supported by the analysis of the quantitative data in ELSA (Lee, Nazroo and Pendleton 2014). However, when they did, their comments suggested that menopauserelated issues, or gynaecological factors, had been the main influencing factors. 
Sex has become a problem since my wife had a hysterectomy and pelvic floor reconstruction, she finds it uncomfortable. My sex drive has always been higher. (Man aged $5^{\mathrm{o}-60}$ )

However, within this context some male participants highlighted the importance of the relationship, reflecting comments made by female participants about the closeness of their relationships in spite of an absence of sexual activity.

No sexual activity with my wife for many years due to problems with 'the change' following hysterectomy but we remain a loving couple. (Man aged 70-8o)

My husband is 82 and has heart and health problems, but is very loving and kind, which I think overrides the non-existent sex. (Woman aged $70-80$ )

Both men and women made comments on relationships, particularly in the context of partner health, and this is explored further in the next section.

\section{Relationships}

Participants viewed sex as important to couple-relationships; however, women more often than men made additional comments about relationships with their partner, other family members, or difficulties within a relationship. Primarily they made reference to sexual activity as being one part of a caring relationship.

The act of sex does not make you 'happy' but having a loving partner does. (Woman aged $5^{\mathrm{o}-60}$ )

The idea of happiness from having a 'loving partner' was implicit in the accounts of other women, where some made reference to having sex solely to please their partners. The importance these women placed on their partner's sexual pleasure superseded that of their own pleasure.

I consider sex to be only part of a caring relationship, and if by taking it gives pleasure to the other, I shall continue as long as able. (Woman aged 6o-70)

If I wasn't dry or I had an orgasm more I'd love it more, but would not refuse my husband out of love for him. (Woman aged 6o-70)

These women saw sex as central to a committed relationship, even though they no longer enjoyed sexual activity themselves. Interestingly, men tended to make reference to taking the lead for sexual activity, which may reflect the traditional (heterosexual) gender relations that the current generation of older people grew up with (Gott 2005). As earlier, the comments made by men tended to be short and to the point. For example:

Sex is part of a married partner's life. (Man aged 8o-9o) 
The relationship was central here, and the wide range of comments indicated that sex and intimacy were firmly embedded within the context of a committed, usually long-term relationship. However, for some couples, the important things in relationships were not always about sexual activities.

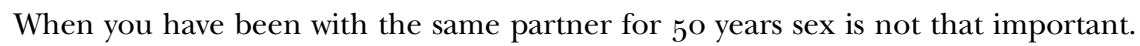
Having the same interests and companionship is more enjoyable. (Woman aged $60-70)$

I don't feel that sex is the most important thing in a relationship. Commitment and care are more, or as, important. (Man age 6o-70)

Thus, many men echoed the views of the women above: that commitment, love and care could be the most important elements of a relationship, over and above sexual activity. This perhaps related to the finding that the nature of sexual intimacy could change over time - sexual desire and the role of sexual intercourse were noted to change as one reached mid-life. But other noted influences included physiological changes, physical absence (separation from the partner due to living in different geographical locations) and the presence, or not, of adult children in the house.

Now too old but my wife and I sleep in the same bed, and kiss and cuddle each other before settling down to sleep. We enjoy each other's company. (Man aged 80-9o)

I just want to say that I would be interested still in a sexual relationship (my husband is not). However, circumstances (adult children still at home) make it difficult even if my husband was interested!! That said, sex has never been the focus of our relationship. (Woman aged $5^{\mathrm{o}-60}$ )

However, some participants noted that sex, at their older age, was as good as it had been at any point in their relationship.

In summary, I am extremely happy with my sexual relationship with my wife and so pleased that sex for both of us is as good as it has ever been, even in the age range of 70-8o. (Man aged 70-8o)

Overall, in the context of the data coded under this theme, there was no clarity across accounts as to whether male or female participants were referring to: changes in their sex lives, a reduction in frequency of sexual activity, or whether they remained satisfied with their relationship regardless of the continuation, or absence, of sexual activity. The third theme of sexual satisfaction and sexual activity then enabled us to explore this in the context of couples' relationships.

\section{Sexual satisfaction and sexual activity}

The analysis of the data revealed that for women and men both sexual acts and the nature of their relationships could contribute to their own sexual 
satisfaction. In terms of age-related changes and sexual satisfaction, some men made reference to their own orgasm, for example not being:

as good now as it used to be. (Man aged 6o-70)

Interestingly, sexual satisfaction for some was flexible in that when their partner lost interest, then they lost desire, which perhaps reflects the satisfaction gained from the relationship overall, as described above, instead of from the sexual act per se.

Issues of sexual problems were also identified as part of this theme. Men mentioned difficulties in orgasm, which related to their erections not being as hard as when younger, and that their female partners seemed to have lost interest in sex. Women mentioned their vaginal problems, such as dryness, and their partner's erection difficulties. Other sexual problems were mentioned too, such as those linked to physical health and the medications used to treat chronic conditions.

My wife doesn't seem to want sex. When we do, I manually bring her to a climax, but found it difficult to eject when we have intercourse. If I masturbate I eject okay. (Man aged 6o-70)

It was clear from the data that sexual problems related to erections and the menopause (desire and vaginal dryness) impacted on the sexual satisfaction and activities of men and women individually and in the context of a relationship.

I believe I suffer from involuntary contraction of the vagina and dryness. This makes penetration by my husband extremely painful and often impossible, which is frustrating for both of us. (Woman aged 6o-70)

I have been having problems keeping an erection and am considering trying Viagra, as I would like to keep my sexual life going as long as I can. (Man aged 70-80)

However, there was also a suggestion of adaption and change in sexual activities to maintain sexual intimacy.

We have oral sex now, but very infrequent, it may be four months since we did it. (Woman aged 80-9o)

For others, there was a mismatch between their sexual satisfaction and preferred sexual activities and those of their partner.

Would like other forms of sex e.g. Anal and oral but my wife will not engage in them. (Man aged 70-80)

Enjoy mild porn on internet $2-3$ times a month, masturbation, interested in keeping things working although nothing possible with wife these days, chance would be a find. (Man aged 80-9o) 
There were also comments about never having been sexually satisfied; based on more personal and individual factors.

I am embarrassed to talk about sex but I want to be honest, I have only had one sexual partner in life and I was not satisfied sexually, I have never had an orgasm. (Woman aged $60-70$ )

The data on sexual satisfaction and sexual activities identified some of the factors that impacted on this in later life. The role that ageing played in this is investigated next.

\section{Ageing and sexuality}

The impact of older age on both men's and women's sexual activities was reflected in the data around issues of personal expectations and experiences, ageing bodies, the responses of health-care services and comparisons to their past sex lives. This theme tended to incorporate the more negative views of how participants felt that growing older had impacted on their sexuality. However, there were also positive perspectives.

I am 75 and still enjoy sex. I don't see why some people say to me 'oh my god sex at your age'. If a couple enjoy it then what's the problem. It relaxes me. (Woman aged $70-80)$

The expectations of other people did not always coincide with the personal expectations of the participants, some of whom challenged the negative stereotype that older people should not be sexually active. Indeed, the thought of losing the capacity to engage in sexual activity could be experienced as regret or relief.

Some time, maybe soon, maybe not I shan't be able to do it anymore and will that be a source of regret or relief to know that biologically speaking my life will no longer serve any purpose? (Man aged 6o-7o)

However, many participants indicated that their sex lives were over and their own expectations were that nothing could change that.

It's a bit late to care about a sex life. Nowt will bring it back. (Man 70-8o)

The analysis also revealed that completing the SRA-Q seemed to trigger reflections on sexually related issues and sexual behaviours of the past. Significant social changes, such as the development and availability of the oral contraceptive pill for women, were noted.

I wish the contraceptive pill had been available when I was young. Fear of getting pregnant was a strong deterrent to normal sexual activity. (Woman aged 70-80)

Another participant also directly referred to his younger self and the focus on sexual desire and masturbation. 
As I am getting older sexually I am reverting back to my teenage years, always ready and wanting sex. Masturbation has become a hobby now. (Man aged $5^{\mathrm{O}-60}$ )

It is interesting that this respondent described having an increased interest in sex now that he was in his fifties, indicating the fluidity in his sexual desire and how this has been experienced at different intensities through his own lifecourse. This contrasts with some older male participants who said that they wished they were in their twenties again, and that while their bodies were not, their minds certainly were.

Don't forget: the mind is still in its 20 even when you get old. (Man 8o-9o)

Indeed, the older body featured prominently in this theme. Male participants made reference to physical and sexual functioning of their bodies and physical changes in their genitalia.

Penis shrunk with age. (Man aged 70-80)

I have a collapsed circumcision \& I have no visible penis since approx 2005!! (Man aged 6o-70)

Within the women's accounts there were instances of both positive and negative experiences of body image directly related to being older women.

My sexual drive declined after my divorce and my menopause. This, however, has not concerned me. I take care of my appearance and body image. (Woman aged $5^{\mathrm{o}-60}$ )

The participant above was keen to state that while she no longer desired sex, her physical appearance remained important to her. However, for the participant quoted below, the changes in the appearance of her older body made her question whether a sexual partner would find her sexually desirable.

I think it would be enjoyable to still have sex, but I no longer have a partner and in any case as I've got older all these lumps and skin tags have appeared and I don't think I would be appealing any more. (Woman aged 70-8o)

This theme then helps illustrate how perceptions of ageing can be linked to some of the sexual difficulties associated with getting older. The added dimension here is the concerns that participants raised about the way that health-care services addressed sexual health and wellbeing needs, which was not always helpful.

Doctors and health care professionals do not seem to give any help re sexual health problems: in my case, erectile dysfunction. (Man aged 70-80)

Indeed, one participant in his eighties reported that his general practitioner (GP) refused to prescribe him Viagra on the basis that it was too expensive. Other participants' comments suggested that they believed their age acted 
as a barrier to them not receiving appropriate help for their sexual concerns.

Have sought help through GP and privately. Very little help available - often feel that you shouldn't be concerned 'at your age'! (Woman aged 60-70)

This response suggested that the social stereotype of an asexual old age limited the help available, through the National Health Service (NHS) and privately, to her for her sexual problem. Others noted that sexual problems were dismissed as being age-related, with the implication that nothing could be done to help or that they should not expect anything different at their age.

The NHS seems reluctant to help with sexual problems in someone of our age. Penetrative sex is incredibly painful and I have been advised it's due to age. (Woman aged $70-80$ )

\section{Discussion}

The analyses presented in this paper show that a range of inter-related factors impact on older people's sexual activities, experiences and attitudes. Four key themes emerged from the data, health, relationships, sexual satisfaction and sexual activities, and ageing and sexuality, which provided new insights into the ways in which men and women, most of whom were in a coupled relationship, experience sex in later life. The wider impact of these issues to our understanding of ageing is now discussed.

Participants indicated that experiences of an individual and her or his partner's health conditions impacted on sexual activities for both men and women. While health problems should not necessarily be a bar to sexual activity, other reviews of the literature have identified that it is important to consider the individual and combined impact of disease processes, treatment impacts, and psychological and relational factors (Verschuren et al. 2010; Wylie, Wood and McManus 2013). Recognising the impact of psychological and mental wellbeing is particularly important, as some of the ELSA participant comments illustrate how depression impacted on the sexual activities for both men and women. This is an important issue as Hartmann's (2007) review of the literature identified that both men and women suffering from all forms of depression are more likely to experience sexual problems, which can be further exacerbated by the side-effects of antidepressant medications. Also others have shown that physical health (in this case cardiovascular disease) impacts on both quality of life and relationship quality (Steptoe, Jackson and Wardle 2016), which in turn may impact on sexual activities. The impact of physical and mental health on 
older people's sexual activities, therefore, needs more attention from health-care practitioners. The issue of partner health impacting on sexual activities is also important.

Verschuren et al. (2010) have also argued that the relationship context of a couple's sexual relationship has been overlooked both in research and clinical practice. This emerged as an important issue in the analysis presented here, which also identified how the nature of sexual intimacy can change over time. A key finding was that even though penetrative and non-penetrative sexual activities changed over time, partnerships can remained satisfying, caring and rewarding. However, an international study of sexual satisfaction and relationship happiness in a coupled relationship identified that men and women (aged 40-70) with higher levels of sexual functioning were more likely to report sexual satisfaction and relationship happiness (Heiman et al. 2011). This association between sexual satisfaction and relationship satisfaction is further supported by Byers (2010) who identified that there is a connection between the quality of a couple's sexual relationship and relationship satisfaction. However, Byers (2010) also identified that the quality of communication between a couple also played an important role, and noted that poor communication within couples over time results in decreased satisfaction in relationship functioning. With regard to the gender difference we noted, with women more likely to make comments about relationships, a study in the United States of America of why people have sex found that women exceeded men in endorsing certain, but not all, of the emotional motivations for sex (Meston and Buss 2007). Therefore, feelings or expressions of love were found to be more important for women, while men were more motivated than women for sex without emotional involvement (Meston and Buss 2007). However, Meston and Buss (2007: 500) did note from their findings that 'both men and women at times desire intimacy and emotional connectedness from sexual activity', which was also reflected in both male and female ELSA respondents here.

The analysis also illustrated how older people adapt their sexual activities and behaviours in the context of health and relationship issues. This is important as the sexual behaviours and activities of older people have historically been under-researched (Penhollow, Young and Denny 2009). In understanding how the frequency of sexual activities might impact on sexual satisfaction, both men and women commented on the effect of the menopause and erectile difficulties. While there are hormonal and physical changes that occur in women, most commonly, but not always, in mid-life, the literature cautions against solely attributing a reduction in sexual activity to the menopause, suggesting that sexual drive, beliefs/values and motivation also play a role in women's sexual desires and activity (Kingsberg 


\section{$5^{14}$ Josie Tetley et al.}

2002). In terms of erectile difficulties, the causes of erectile dysfunction have been recognised to be underpinned by both physical and psychosocial problems (Shamloul and Ghanem 2013). The fact that the menopause and erectile difficulties cannot be understood as solely physiological is important, as these do impact on individual and partnered sexual satisfaction and activities (Moreira et al. 2008). Older people experiencing problems related to these may then benefit from relationship and lifestyle advice as well as psycho-sexual support that goes beyond the use of prescribed medications (Kingsberg 2002; Shamloul and Ghanem 2013).

Other comments that provide additional context to the initial analysis also raise issues of gender, generation effects and engagement in sexual activities that differ from penetrative vaginal sex. The comments from participants that focused on anal sex, pornography and masturbation were from a small number of male participants, a finding that has been reflected in a study by Kontula and Haavio-Mannila (2009), who found that attitudes towards certain sexual issues, such as sex without love and use of pornography, were more common in men. However, the expressed desire for anal and oral sex from a man aged $70-8 \mathrm{o}$ is significant, as the literature suggests that there is an under-reporting at all ages of 'taboo' sexual behaviours such as heterosexual anal sex (McBride and Fortenberry 2010). The reporting of oral sex from a woman aged $80-90$ also contrasts with the assumption of a sharp generational divide in sexual experiences and attitudes, and thus supports Waite's (2010) argument that people who came of age in the 1960 are more likely to have a more liberal attitude to sex. Reflecting on these issues in the context of the ELSA cohort is important, as historical, social and cultural dimensions can influence men and women's sexual activities, behaviours and experiences (Gott 2005). It has been argued that people identified as 'baby boomers', i.e. the younger members of the ELSA cohort, may be more likely to challenge perceptions of 'normative' sexual activity in later life (Gott 2006), but the ELSA data illustrate that generalisations about sexual activities based on cohort assumptions do not necessarily hold true.

Following on from the discussion of sexual activity and sexual satisfaction, participants' comments also identify how their past and present experiences of ageing and sexuality impacted on their current attitudes to, experiences of and engagement with sexual activities. The fact that some older people expressed negative thoughts about their ageing bodies when trying to negotiate sexuality in later life is not surprising. Indeed, the literature suggests that it is not uncommon for people to think that older people are asexual, that sexual activity in later life is funny and that sexual activity in later life is disgusting (Kessel 2001; Taylor and Gosney 2011; Vares 2009). Ageist views of sexuality may then have influenced participants' 
responses and additional comments. Indeed, Gott (2005) argues that a view of later life as asexual has come about because ageist views in society equate sexuality (and sexual activity) to health, power and youth, characteristics which tend not to be associated with older people. Following on from this, it is probably not surprising that for some respondents reflecting on their sexual activities triggered comments about their younger lives.

The physical age-related changes, such as those noted by female ELSA participants, resonate with the work of Warren and Richards (2012), who found that women's perceptions of skin, hair and general appearance are central to how they understand and experience ageing processes. While only one man in the present study made a comment on the size of his penis, other men commented on the physical and sexual functioning of their bodies. The concerns about the function and aesthetics of the male penis have been highlighted by Flowers et al. (2013), who argue that medical discourses have traditionally focused on the function of the penis in ways that have contributed to the development and use of pharmaceutical interventions such as Viagra. The developments of interventions focused on erectile difficulties may then have contributed to ELSA male participants' responses about sexual satisfaction and their ability to orgasm or maintain erections comparable to when they were younger. In addition, Flowers et al. (2013) suggest that societal changes are increasingly putting men under pressure to think about the size and appearance of their penises. This view is supported by two studies that have found that male penis size was associated with overall body image satisfaction (Lever, Frederick and Peplau 2006; Veale et al. 2015). The move towards increased medicalisation and the use of cosmetic surgery in relation to sexuality in later life is, however, in contrast to other comments reported here that suggest that consulting the medical profession about issues of sexual activities and relationships was difficult and that older people felt their concerns were not taken seriously.

The fact that the ELSA participants reported that health professionals do not easily engage in conversations about sexual health is important as the responses from participants identify that older people do want to talk to health professionals when they have sexual concerns. The need for more proactive and effective discussions and advice around sexual concerns and health has also been raised as an issue of concern in the context of ELSA and other studies of sexual activities in later life (Corona et al. 2013; Gott 2005; Hinchliff and Gott 2011; Steptoe, Jackson and Wardle 2016). In addition to the challenges around talking about sexual activities with health professionals, the comments made also suggest that when both men and women had raised concerns about their sexual health these were not taken seriously, or that they were dismissed on the 
grounds of age. Moreover, in a survey of geriatricians in the United Kingdom (UK), Balami (2011) found that taking a sexual history was thought it to be irrelevant and this was infrequently done. Meiner (2014) suggests that nurses have a pivotal role in assessing older people's sexual activities, specifically around identifying concerns that affect sexual functioning and sexual health. This is important, as Hinchliff and Gott (2011) have identified that specialist sexual health services for older people do not exist, which raises issues for health-care education and practice. While resources aimed at improving sexual health in later life should provide physical, psychological and relationship support, the importance of providing appropriate sexual health services for older adults is emphasised in the context of increasing diagnoses of sexually transmitted infections in the over fifties in the UK (Public Health England 2014).

\section{Limitations and conclusion}

In discussing the findings generated by the qualitative ELSA data, it is important to highlight that people's responses were given in the context of responding to the structured questionnaire (the SRA-Q). As noted earlier, people's responses were limited to a short comment box. Moreover, ELSA did not attempt to over-sample sexual minorities and the results presented here do not shed light on the circumstances pertinent to older LGBT people in relation to ageing and sexual activity. Despite this limitation, the findings do illustrate a diversity of sexual attitudes, activities and experiences, and identify the ways in which physical and emotional sexual intimacy change as people age into their seventies, eighties and nineties. The finding that sexual activities in later life encompass more than penile-vaginal intercourse also challenges more heteronormative ideas about sexual relationships (Allen and Roberto 2009). This in itself is an important observation, as remaining sexually active into later life in a range of ways may confer benefits to people's physiological and psychological wellbeing (Hinchliff and Gott 2004, 2011; Syme et al. 2013). In addition, this analysis of the qualitative ELSA data extends current understandings about the ways in which health, relationships, sexual satisfaction and ageing can impact on the self-reported sexual activities of older men and women. Taking account of these factors is relevant to ageing studies, as our findings suggest that those who appeared to be most happy with their sexual activities positively commented on the quality of their relationships, or how they had adapted to maintain their sexual activity or sexual contact. This is consistent with reports and commentaries from the wider sexual health and ageing literature, which argue that being able to adapt to a more sensory sexuality, 
with less focus on penetrative sex, can make an important contribution to continued sexual activities into later life (Corona et al. 2013; Gott 2005; Hinchliff and Gott 2004).

Ultimately, the findings from the qualitative ELSA data presented in this paper have important implications for research and practice. For gerontologists, the findings illustrate that there is a need for more research that explores how issues of cohort and generational factors, including attitudes and beliefs, impact on, and/or challenge, people's experiences and perceptions of sexual activities' in later life. For health-care practice, the findings demonstrate how more proactive discussions around sexual function and activities, particularly in the context of long-term health problems, can benefit the health and wellbeing of older people. Moreover, as people predominantly engage in sexual activities in the context of a relationship, when people seek help for long-term health conditions and/or issues related to sexual functioning, support for both partners is likely to be more effective.

\section{Acknowledgements}

We thank the study participants. D.M.L. was a Research into Ageing Fellow up until June 2016. The ELSA study was funded by the National Institute on Aging (grants ${ }_{2} \mathrm{RO}_{1} \mathrm{AG}_{7} 644^{-\mathrm{O}} \mathrm{A}_{1}$ and $\left.{ }_{2} \mathrm{RO}_{1} \mathrm{AGol}_{17} 644\right)$ and a consortium of UK Government departments co-ordinated by the Office for National Statistics. J.N. and D.M.L. are supported by the fRaill project (grant MRC G1001375/1) as part of the cross-research council Life Long Health and Wellbeing Programme. Manchester Metropolitan University funded the scanning and transcribing of the qualitative data reported in this paper.

\section{References}

Allen, K. R. and Roberto, K. A. 2009. From sexism to sexy: challenging young adults' ageism about older women's sexuality. Sexuality Research and Social Policy, 6, 4, 13-24.

Araujo, A. B., Mohr, B. A., Mohr, M. S. and McKinlay, J. B. 2004. Changes in sexual function in middle-aged and older men: longitudinal data from the Massachusetts Male Aging Study. Journal of the American Geriatrics Society, 52, 9, $1502-9$.

Balami, J. S. 2011 . Are geriatricians guilty of failure to take a sexual history? Journal of Clinical Gerontology and Geriatrics, 2, 1, 17-20.

Brooks, J. and King, N. 2012. Qualitative psychology in the real world: the utility of template analysis. Paper presented at the British Psychological Society Annual Conference, 18-20 April, London. Available online at http://eprints.hud.ac.uk/ ${ }_{13} 65^{6}$ [Accessed December 2015].

Brooks, J., McCluskey, S., Turley, E. and King, N. 2015. The utility of template analysis in qualitative psychology research. Qualitative Research in Psychology, 12 , 2, 202-22.

Byers, E. S. 2010. Relationship satisfaction and sexual satisfaction: a longitudinal study of individuals in long-term relationships. Journal of Sex Research, 42, 2, 37-41. 
Carpenter, L. M. and DeLameter, J. (eds) 201 2. Sex for Life: From Virginity to Viagra, How Sexuality Changes Throughout Our Lives. New York Press, New York.

Carpenter, L. M., Nathanson, C. A. and Kim, Y.J. 2006. Sex after 40? Gender, ageism, and sexual partnering in midlife. Journal of Aging Studies, 2o, 2, 93-106.

Corona, G., Rastrelli, G., Maseroli, E., Forti, G. and Maggi, M. 2013. Sexual function of the ageing male. Best practice \& research. Clinical Endocrinology E Metabolism, 27, $4,5^{81-601 .}$

Cox, J. W. 2008. Template analysis. In Thorpe, R. and Holt, R. (eds), The Sage Dictionary of Qualitative Management Research. Sage, London, 220-2.

Crabtree, B. F. and Miller, W. L. 1999. Using codes and code manuals: a template organizing style of interpretation. In Crabtree, B. F. and Miller, W. L. (eds), Doing Qualitative Research. Second edition, Sage, Newbury Park, California, $163^{-}$ 77 .

DeLamater, J. 2012. Sexual expression in later life: a review and synthesis. Journal of Sex Research, 49, 2/3, $125^{-41 .}$

DeLamater, J. and Koepsel, E. 2015. Relationships and sexual expression in later life: a biopsychosocial perspective. Sexual and Relationship Therapy, 3o, 1, 37-59.

DeLamater, J. D. and Sill, M. 2005. Sexual desire in later life. Journal of Sex Research, 42, 2, $138-49$.

Domoney, C. 2009. Sexual function in women: what is normal? International Urogynecology Journal, 2o, supplement 1, S9-17.

Field, N., Mercer, C. H., Sonnenberg, P., Tanton, C., Clifton, S., Mitchell, K. R., Erens, B., Macdowall, W., Wu, F. C., Datta, J., Jones, K. G., Stevens, A., Prah, P., Copas, A.J., Phelps, A., Wellings, K. and Johnson, A. M. 2013. Associations between health and sexual lifestyles in Britain: findings from the third National Survey of Sexual Attitudes and Lifestyles (Natsal-3). Lancet, 382, 9907, 1830-44.

Fileborn, B., Thorpe, R., Hawkes, G., Minichiello, V. and Pitts, M. 2015 . Sex and the (older) single girl: experiences of sex and dating in later life. Journal of Aging Studies, 33, April, 67-75.

Flowers, P., Langdridge, D., Gough, B. and Holliday, R. 2013. On the biomedicalisation of the penis: the commodification of function and aesthetics. International Journal of Men's Health, 12, 2, $121-37$.

Galinsky, A. M. and Waite, L. J. 2014 . Sexual activity and psychological health as mediators of the relationship between physical health and marital quality. Journals of Gerontology: Psychological Sciences and Social Sciences, 69B, 3, 482-92.

Gledhill, S. and Schweitzer, R. D. 2014. Sexual desire, erectile dysfunction and the biomedicalization of sex in older heterosexual men. Journal of Advanced Nursing, 7o, $4,894-903$.

Gott, M. 2005. Sexuality, Sexual Health and Ageing. Open University Press, Maidenhead, UK.

Gott, M. 2006. Sexual health and the new ageing. Age and Ageing, 35, 2, 106-7.

Gott, M. and Hinchliff, S. 2003. How important is sex in later life? The views of older people. Social Science $\mathcal{E}$ Medicine, 56, 8, 1617-28.

Hartmann, U. 2007. Depression and sexual dysfunction. Journal of Men's Health $\mathcal{F}^{2}$ Gender, 4, 1, 18-25.

Hayes, R. and Dennerstein, L. 2005. The impact of aging on sexual function and sexual dysfunction in women: a review of population based studies. Journal of Sexual Medicine, 2, 3, 317-30.

Heiman, J. R., Long, J. S., Smith, S. N., Fisher, W. A., Sand, M. S. and Rosen, R. C. 2011. Sexual satisfaction and relationship happiness in midlife and older couples in five countries. Archives of Sexual Behavior, 4o, 4, 741-53. 
Hinchliff, S. and Gott, M. 2004. Intimacy, commitment, and adaptation: sexual relationships within long-term marriages. Journal of Social and Personal Relationships, 21, 5, 595-6o9.

Hinchliff, S. and Gott, M. 2011. Seeking medical help for sexual concerns in midand later life: a review of the literature. Journal of Sex Research, 48, 2/3, 106-17.

Hollander, I. 2006. Viagra's rise above women's health issues: an analysis of the social and political influences on drug approvals in the United States and Japan. Social Science Ẽ Medicine, 62, 3, 683-93.

Jung, A. and Schill, W.-B. 2004. Male sexuality with advancing age. European Journal of Obstetrics, Gynecology, and Reproductive Biology, $113,2,123-5$.

Karraker, A. and DeLamater, J. 2013. Past-year sexual inactivity among older married persons and their partners. Journal of Marriage and Family, 75, February, $142-63$.

Karraker, A., DeLamater, J. and Schwartz, C. R. 2011 . Sexual frequency decline from midlife to later life. Journals of Gerontology: Psychological Sciences and Social Sciences, 66B, $4,5^{\mathrm{O} 2-12 .}$

Katz, S. and Marshall, B. 2o03. New sex for old: lifestyle, consumerism, and the ethics of aging well. Journal of Aging Studies, 17, 1, 3-16.

Kessel, B. 2001. Sexuality in the older person. Age and Ageing, 3o, 2, $121-4$.

King, N. 2004. Using templates in the thematic analysis of text. In Symon, G. and Cassell, C. (eds), Essential Guide to Qualitative Methods in Organizational Research. Sage, London, $25^{6-70 .}$

King, N. 201 2. Doing template analysis. In Symon, G. and Cassell, C. (eds), Qualitative Organizational Research: Core Methods and Current Challenges. Sage, London, $4^{26}{ }^{5} 5^{\mathrm{O}}$

King, N. and Horrocks, C. 2010 . Interviews in Qualitative Research. Sage, London.

Kingsberg, S. A. 2002. The impact of aging on sexual function in women and their partners. Archives of Sexual Behavior, 31, 5, 431-7.

Kontula, O. and Haavio-Mannila, E. 20og. The impact of aging on human sexual activity and sexual desire. Journal of Sex Research, 46, 1, 46-56.

Laumann, E. O., Nicolosi, A., Glasser, D. B., Paik, A., Gingell, C., Moreira, E. and Wang, T. 2005. Sexual problems among women and men aged $40-80$ y: prevalence and correlates identified in the Global Study of Sexual Attitudes and Behaviors. International Journal of Impotence Research, 1 7, 1, 39-57.

Lawton, Z., Callister, P. and Street, B. 2010. Older Women-Younger Men Relationships: The Social Phenomenon of 'Cougars': A Research Note. Institute of Policy Studies, Wellington.

Lee, D. M., Nazroo, J., O’Connor, D. B., Blake, M. and Pendleton, N. $2016 a$. Sexual health and well-being among older men and women in England: findings from the English Longitudinal Study of Ageing. Archives of Sexual Behavior, 45, 1, 133-44.

Lee, D. M., Vanoutte, B., Nazroo, J. and Pendleton, N. 2016b. Sexual health and positive subjective well-being in partnered older men and women. Journals of Gerontology: Psychological Sciences and Social Sciences, 71B, 4, 698-710.

Lee, D. M., Nazroo, J. and Pendleton, N. 2014. Sexual health, quality-of-life and wellbeing among older men and women in England: a dyadic analysis from the English Longitudinal Study of Ageing. The Gerontologist, 54, supplement 2, 564 .

Lever, J., Frederick, D. A. and Peplau, L. A. 2006. Does size matter? Men's and women's views on penis size across the lifespan. Psychology of Men and Masculinity, 7, 3, 129-43.

Lindau, S. T., Schumm, L. P., Laumann, E. O., Levinson, W., O’Muircheartaigh, C. A. and Waite, L. J. 2007. A study of sexuality and health among older adults in the United States. The New England Journal of Medicine, 357, 8, 762-74. 
McBride, K. R. and Fortenberry, J. D. 2010. Heterosexual anal sexuality and anal sex behaviors: a review. Journal of Sex Research, 47, 2, 123-36.

Meiner, S. E. 2014. Gerontological Nursing. Fifth edition, Elsevier, Maryland Heights, Missouri.

Meston, C. M. and Buss, D. M. 2007. Why humans have sex. Archives of Sexual Behavior, 36, 4, 477-507.

Montemurro, B. and Siefken, J. M. 2014. Cougars on the prowl? New perceptions of older women's sexuality. Journal of Aging Studies, 28, January, 35-43.

Moreira, E. D., Glasser, D. B. Nicolosi, A., Duarte, F. G. and Gingell, C. 2008. Sexual problems and help-seeking behaviour in adults in the United Kingdom and continental Europe. BJU International, 101, 8, 1005-11.

Oliffe, J. 2005. Constructions of masculinity following prostatectomy-induced impotence. Social Science $\mathcal{E}$ Medicine, 6o, 10, 2249-59.

Penhollow, T. M., Young, M. and Denny, G. 2009. Predictors of quality of life, sexual intercourse, and sexual satisfaction among active older adults. American Journal of Health Education, 4o, 1, 14-22.

Public Health England 2014. Table 2: STI Diagnoses and Rates by Gender, Sexual Risk and Age Group, 20IO-20I4. Available online at https://www.gov.uk/govern ment/uploads/system/upload [Accessed 26 May 2016].

Rosen, R. C. and Bachmann, G. A. 2008 Sexual well-being, happiness, and satisfaction, in women: the case for a new conceptual paradigm. Journal of Sex E Marital Therapy, 34, 4, 291-7.

Schwarz, E. R. 2005. Sexual dysfunction and its relation to heart disease. International Journal of Impotence Research, $\mathbf{1 7}$, supplement $1, \mathrm{~S}_{1-3}$.

Shamloul, R. and Ghanem, H. 2013. Erectile dysfunction. Lancet, 381, 9861, 15365 .

Steptoe, A., Breeze, E., Banks, J. and Nazroo, J. 2013. Cohort profile: the English Longitudinal Study of Ageing. International Journal of Epidemiology, 42, 6, 1640-8.

Steptoe, A., Jackson, S. E. and Wardle, J. 2016. Sexual activity and concerns in people with coronary heart disease from a population-based study. Heart. Available online at http://heart.bmj.com/content/early/2016/04/28/heartjnl-2015-308993.full [Accessed 3o May 2016].

Syme, M. L., Klonoff, E. A., Macera, C. A. and Brodine, S. K. 2013 . Predicting sexual decline and dissatisfaction among older adults: the role of partnered and individual physical and mental health factors. Journals of Gerontology: Psychological and Social Sciences, 68B, 3, 323-32.

Taylor, A. and Gosney, M. A. 2011 . Sexuality in older age: essential considerations for healthcare professionals. Age and Ageing, 4o, 5, 538-43.

ten Kleij, F. and Musters, P. A. 2003. Text analysis of open-ended survey responses: a complementary method to preference mapping. Food quality and preference, 14, 1, $43^{-} 5^{2}$.

Tiefer, L. 2007. Beneath the veneer: the troubled past and future of sexual medicine. Journal of Sex and Marital Therapy, 33, 5, 473-7.

Vares, T. 2009. Reading the 'sexy oldie': gender, age(ing) and embodiment. Sexualities, 12, 4, 503-24.

Vares, T., Potts, A., Gavey, N. and Grace, V. M. 2007. Reconceptualizing cultural narratives of mature women's sexuality in the Viagra era. Journal of Aging Studies, 2 1, 2, $153-64$.

Veale, D., Miles, S., Bramley, S., Muir, G. and Hodsoll, J. 2015. Am I normal? A systematic review and construction of nomograms for flaccid and erect penis length and circumference in up to $155^{21}$ men. BJU International, 115, 6, 978-86. 
Verschuren, J.E. A., Enzlin, P., Dijkstra, P. U., Geertzen, J.H. B. and Dekker, R. 2010. Chronic disease and sexuality: a generic conceptual framework. Journal of Sex Research, 47, 2, 153-70.

Waite, L. J. 2010. Sexuality has no expiration date. American Sociological Association, 9, $3,605^{2}$.

Waite, L. and Das, A. 2010. Families, social life and wellbeing at older ages. Demography, 47, supplement, S87-109.

Waring, T. and Wainwright, D. 2008. Issues and challenges in the use of template analysis: two comparative case studies from the field. The Electronic Journal of Business Research Methods, 6, 1, 85-94.

Warren, L. and Richards, N. 201 2. I don't see many images of myself coming back at myself: representations of women and ageing. In Virpi, Y. (ed.), Representing Ageing: Images and Identities. Palgrave Macmillan, Basingstoke, UK, 149-68.

Wylie, K. R., Wood, A. and McManus, R. 2013. Sexuality and old age. Bundesgesundheitsblatt, Gesundheitsforschung, Gesundheitsschutz, 56, 2, 223-30.

Accepted 8 September 2016; first published online I 5 November 2 о I 6

Address for correspondence:

Josie Tetley,

Faculty of Health, Psychology and Social Care,

Manchester Metropolitan University,

Birley Building,

53 Bonsall Street,

Manchester M15 6GX, UK

E-mail: j.tetley@mmu.ac.uk 